\title{
atherosclerosis
}

Atherosclerosis 122 (1996) 245-253

\section{Autoantibodies against MDA-LDL in subjects with severe and minor atherosclerosis and healthy population controls}

\author{
Lucy P.L. van de Vijver ${ }^{\mathrm{a}, \mathrm{b}}$, Roland Steyger ${ }^{\mathrm{c}}$, Geert van Poppel ${ }^{\mathrm{a}}$, Jolanda M.A. Boer ${ }^{\mathrm{d}}$, \\ Dick A.C.M. Kruijssen ${ }^{\mathrm{e}}$, Jacob C. Seidell ${ }^{\mathrm{d}}$, Hans M.G. Princen ${ }^{\mathrm{c}, *}$ \\ ${ }^{a}$ Department of Epidemiology, TNO Nutrition and Food Research Institute Zeist, The Netherlands \\ ${ }^{\mathrm{b}}$ Department of Epidemiology and Biostatistics, Erasmus University Rotterdam, The Netherlands

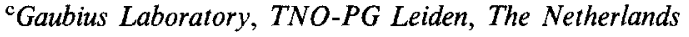 \\ 'Department of Chronic Diseases and Environmental Epidemiology, National Institute of Public Health and Environmental \\ Protection Bilthoven, The Netherlands \\ ${ }^{\mathrm{e}}$ Department of Cardiology, Zuiderziekenhuis, and Sticares Foundation, Rotterdam, The Netherlands
}

Received 31 July 1995; revised 3 November 1995; accepted 8 November 1995

\begin{abstract}
Autoantibodies against oxidized low-density lipoprotein (LDL) have been reported to be associated with atherosclerosis. However, data are not consistent.

We compared the titres of autoantibodies to malondialdehyde-modified LDL in three groups, a case group with angiographically documented severe coronary stenosis ( $>80 \%$ stenosis in at least 1 vessel, $n=47$ ), a hospital control group with minor stenosis on the coronary angiography ( $<50 \%$ stenosis in all three major vessels, $n=47)$ and a healthy population control group with no history of coronary heart disease $(n=49)$. Age ranged from 26 to 68 years. Subjects were frequency-matched for gender distribution and storage time of the blood samples. No relevant differences in autoantibody titre between case and control groups were found. The mean autoantibody titres $( \pm$ S.D.) were $1.44 \pm 1.82,1.46 \pm 1.40$ and $1.62 \pm 1.95$ for cases, hospital controls and population controls, respectively. No correlations were found between autoantibody titre and age, number of cigarettes smoked and LDL or total cholesterol. Autoantibody titres were correlated with body mass index $(r=0.2)$ and high-density lipoprotein (HDL) $(r=-0.2)$. Odds ratios (OR) were calculated by tertiles of autoantibody titres for the hospital control group and the population control group, respectively. Age-adjusted OR $(95 \%$ confidence interval) for medium and high compared to low autoantibody titre were $0.76(0.27-2.14)$ and $1.09(0.39-2.95)$ for the comparison between cases and hospital controls and $1.09(0.39-3.07)$ and $0.90(0.32-2.56)$ for the comparison between cases and population controls. Adjustment for gender, body mass index, smoking habits and HDL yielded essentially the same results.

This study does not support an association between autoantibody titres to oxidized LDL and the extent of coronary stenosis.
\end{abstract}

Keywords: LDL oxidation; Atherosclerosis; Cardiovascular diseases; Autoantibodies

\footnotetext{
* Corresponding author, Gaubius Laboratory, TNO-PG, P.O. Box 2215, 2301 CE LEIDEN, The Netherlands. Tel.: + 3171 5181471; fax: + 3171 5181904; e-mail: jmg.princen@pg.tno.nl
} 


\section{Introduction}

Studies implying that oxidative modification of low-density lipoprotein (LDL) takes place in vivo and may play an important role in atherogenesis have accumulated over recent years $[1-4]$. Oxidized LDL can activate endothelial cells and induce endothelial damage, thereby allowing blood elements and monocytes to enter the sub-endothelial space, which is the beginning of the atherogenic process. As a consequence of oxidation, the uptake of LDL by macrophages is accelerated and foam cells are formed. Furthermore, modified LDL is immunogenic and has the ability to induce the formation of autoantibodies [4,5]. Autoantibodies against epitopes of oxidized LDL have been found in several studies in both human [6-15] and rabbit $[6,15,16]$ plasma and atherosclerotic lcsions, however data on the relation between autoantibody titres and coronary atherosclerosis are not consistent $[6-10,12,13,17-$ 19]. Though the LDL-oxidation hypothesis is attractive in explaining the mechanism of development of atherosclerosis, direct evidence from human studies is still scarce.

To investigate the association between autoantibody titres and atherosclerosis, we studied autoantibody titres of three groups differing in levels of coronary artery disease, namely a group of patients with angiographically documented severe atherosclerosis, a group with angiographically documented minor or non-atherosclerosis and a population-based group with no history of cardiovascular disease (CVD).

\section{Subjects and methods}

\subsection{Study population}

Groups of patients and hospital controls were selected from participants in a previous hospitalbased case-control study on angiographically documented CVD and plasma levels of cholesterol oxidation products. A group of population controls consisted of participants in the Dutch National Cardiovascular Disease Risk Factor Monitoring Project [20]. The hospital groups con- sisted of patients who had undergone a coronary angiography for suspected CVD in the period 1991 and 1992 in Rotterdam. Ineligible were those patients: over 68 years of age; with a previous bypass surgery; with a myocardial infarction (MI) in the 12 months prior to the study period; under cardiac care for more then 2.5 years; in whom more then 2 months elapsed between angiography and case selection; who had diabetes mellitus, liver, kidney or thyroid disease, or showed evidence of alcohol or drug abuse. Of the 387 patients eligible for this study, 51 refused to participate, 22 could not be contacted or were otherwise indisposed and 7 had died. From the remaining 307 patients, cases were selected on the basis of having more then $80 \%$ stenosis in at least one of the three major coronary vessels, and controls having less then $50 \%$ stenosis in all three major coronary vessels. This left 159 patients (80 cases and 79 controls) for the original study. For the study reported here, 50 cases and 48 controls were randomly selected for determination of plasma autoantibodies.

The population control group is a sample out of 36000 participants in the Cardiovascular Disease Risk Factor Monitoring Project (1987-1991) [20]. For the original study, a random sample of men and women aged 20-59 were selected from the civil registry of three cities in the Netherlands. The study was performed at the basic health service in each city. For the study reported here, the following selection criteria were used: domiciled in Amsterdam, the Netherlands, without use of hypercholesterolaemic drugs, not under cardiac care, no heart surgery (such as bypass surgery), without a myocardial infarction. The 51 persons selected were frequency-matched for gender distribution and storage time of the blood samples to subjects of the hospital study.

\subsection{Data collection}

For all three groups, information on medical history, use of medication, dietary, smoking and drinking habits, occupation and family history of CVD was obtained through a questionnaire. Further data on height, weight and blood pressure were gathered. The hospital cases and controls 
were seen within 2 months after angiography. Fasting venous blood samples were collected into a $10 \mathrm{ml}$ EDTA vacutainer tube and the isolated plasma was stored at $-80^{\circ} \mathrm{C}$. For the population control group, non-fasting venous blood samples were collected in $10 \mathrm{ml}$ EDTA vacutainer tubes and after centrifugation plasma was stored at $-20^{\circ} \mathrm{C}$. The mean storage period of blood samples was $31 \pm 3$ months (mean \pm S.D.). Storage periods for cases and control groups were similar.

\subsection{Measurement of anti-MDA-modified $L D L$ autoantibodies}

Autoantibody titres were measured by bi-site sandwich ELISA using polystyrene microtitre plates (Greiner, number 655001, Alphen a/d Rijn, The Netherlands). The microtitre plates were coated with MDA-LDL (malondialdehydemodified LDL) as antigen $(10 \mu \mathrm{g} / \mathrm{ml}, 100 \mu \mathrm{l} /$ well $)$ in phosphate-buffered saline (PBS) for $16 \mathrm{~h}$ at $4^{\circ} \mathrm{C}$. Plates were washed 4 times with PBS and the residual binding sites were blocked with $1 \%(\mathrm{w} / \mathrm{v})$ casein (Merck) in PBS (200 $\mu 1 /$ well) for $2 \mathrm{~h}$ at room temperature. Plates were washed 4 times with PBS, $100 \mu 1 /$ well of diluted samples for autoantibody determination was added, and the plates were incubated for $16 \mathrm{~h}$ at $4^{\circ} \mathrm{C}$. Five dilutions, 1:8, 1:16, 1:24, 1:32, 1:64 ( $/ \mathrm{v})$, in blocking buffer containing $0.05 \%(\mathrm{w} / \mathrm{v})$ Tween 20 (Merck) were applied. After washing 5 times with PBS containing $0.05 \%(\mathrm{w} / \mathrm{v})$ Tween $20,100 \mu 1 /$ well goat-anti-human IgG-Fc fragment conjugated to horseradish peroxidase (Nordic, Tilburg, The Netherlands), diluted 1:11000 in blocking buffer containing $0.1 \%(\mathrm{w} / \mathrm{v})$ casein and $0.05 \%(\mathrm{w} / \mathrm{v})$ Tween 20, was added and the plates were incubated for $2 \mathrm{~h}$ at $37^{\circ} \mathrm{C}$. Plates were washed 4 times and the peroxidase-labelled conjugate was visualized using 3,3',5,5'-tetramethylbenzidine and $\mathrm{H}_{2} \mathrm{O}_{2}$ as substrate mixture [21] (Organon Technika BV, Boxtel, The Netherlands). Each microtitre plate contained equal numbers of samples from the three study groups.

Extensively modified MDA-LDL was used and prepared essentially as described by Palinski et al. [6] by incubating $1 \mathrm{mg} / \mathrm{ml} \mathrm{LDL}$ (prepared from pooled plasma from 5 male and 7 female healthy volunteers aged $21-35$ ) in PBS, $\mathrm{pH} 7.4$ for $4 \mathrm{~h}$ at $37^{\circ} \mathrm{C}$ with $0.1 \mathrm{M}$ MDA, freshly prepared from malonaldehyde-bis-dimethylacetal (Kodak Eastman Co.). After conjugation, MDA-LDL was extensively dialysed against PBS and stored in the presence of $10 \%$ sucrose at $-80^{\circ} \mathrm{C}$. As additional antigen, native LDL (prepared from the above mentioned pool) was used in the assay. This LDL was protected from oxidation by addition of 10 $\mu \mathrm{M}$ EDTA and $20 \mu \mathrm{M}$ butylated hydroxytoluene (Sigma) to PBS and stored in the presence of $10 \%$ sucrose at $-80^{\circ} \mathrm{C}$.

Each microtitre plate contained a dilution series $(1: 8,1: 16,1: 24,1: 32,1: 64 \%)$ of the above-mentioned pool plasma in triplicate, which was used as a reference standard. From the response of these dilution series, a reference line for autoantibody response was constructed. Intra- and interassay coefficients of variation were $6.0 \%$ and $8.3 \%$, respectively, for the reference curves. The autoantibody titre is defined as the ratio between the dilution on the reference line belonging to the autoantibody response in the sample and the original dilution of the sample and is, in general, the mean of the four autoantibody titres obtained at dilutions 1:8, 1:16, 1:24 and 1:32 (v/v). In most cases, the optical density (OD) at the 1:64 ( $/ / v)$ dilution was near the background and deviated from the linear curve. This dilution was then omitted from the calculation. The slopes of the calibration curve constructed with reference standard and of the curves of the individual samples from the patient group and the control groups were not identical. About $15 \%$ of the sample curves deviated from the reference curve, indicating that the values calculated for the human samples can only be considered as indicators of autoantibody concentrations. This allows comparisons between different samples but cannot be considered as an accurate measure of the absolute autoantibody mass in each sample.

Alternatively, data are expressed as the absolute value for the ratio of autoantibody binding to MDA-LDL/native LDL (both as OD), as applied by Salonen et al. [9]. The presented value is the mean of the ratios obtained at dilutions 1:8 and $1: 32$, as the response to native LDL was only measured at these dilutions. Binding to native 
Table 1

Baseline characteristics (mean \pm S.D.)

\begin{tabular}{|c|c|c|c|}
\hline & Cases $(n=47)$ & Hospital controls $(n=47)$ & Population controls $(n=49)$ \\
\hline Age (years) & $54.2 \pm 8.9$ & $53.5 \pm 9.2$ & $49.6 \pm 7.8^{*, * *}$ \\
\hline Body mass index $\left(\mathrm{kg} / \mathrm{m}^{2}\right)$ & $26.2 \pm 3.3$ & $25.4 \pm 2.8$ & $25.9 \pm 3.4$ \\
\hline Plasma cholesterol (mmol/1) & $6.3 \pm 0.9$ & $5.9 \pm 1.1$ & $5.6 \pm 1.0^{*}$ \\
\hline HDL-cholesterol (mmol/l) & $1.1 \pm 0.3$ & $1.3 \pm 0.4^{*}$ & $1.0 \pm 0.3^{*}, * *$ \\
\hline LDL-cholesterol (mmol/1) & $4.4 \pm 0.8$ & $4.0 \pm 1.0^{*}$ & $3.9 \pm 0.9^{*}$ \\
\hline Plasma cholesterol/HDL & $6.0 \pm 1.6$ & $4.9 \pm 1.7^{*}$ & $6.3 \pm 1.9^{* *}$ \\
\hline Plasma triglycerides (mmol/l) & $1.8 \pm 0.8$ & $1.5 \pm 0.8^{*}$ & $1.7 \pm 0.9$ \\
\hline Systolic pressure (mmHg) & $135.0 \pm 19.4$ & $134.0 \pm 15.1$ & $127.0 \pm 16.5^{* * * *}$ \\
\hline Diastolic pressure $(\mathrm{mmHg})$ & $84.8 \pm 10.6$ & $83.4 \pm 10.9$ & $79.3 \pm 10.3^{*}$ \\
\hline$\%$ Male & 68.1 & 68.1 & 67.3 \\
\hline$\%$ Smokers & 25.5 & 27.7 & 38.8 \\
\hline
\end{tabular}

*significant difference $(P<0.05)$ with cases

${ }^{* *}$ significant difference $(P<0.05)$ with hospital controls

LDL, considered as a non-specific control, is defined as the ratio between the autoantibody response in the sample to native LDL (as OD) and the autoantibody response in the reference standard to native LDL (as OD).

\subsection{Analytical measurements}

HDL-cholesterol and triglycerides were determined as described by Sullivan et al. [22] and Warnick et al. [23]. Total-cholesterol was determined with a spectrum analyser (Abbott Laboratories, USA) with CHOD-PAP reagent (cat. no. 236691, Boehringer Mannheim). LDL-cholesterol was calculated with the Friedewald formula [24]. With this formula, triglyceride concentrations must not exceed $4.52 \mathrm{mmol} / 1$ [25]. Subjects who had a triglyceride level above 4.52 were excluded from further analysis ( 3 cases, 1 hospital control and 2 population controls).

\subsection{Data analysis}

Data analysis was conducted using the BMDP statistical package [26]. Basic characteristics for the three groups were compared by Student's $t$-test for unpaired samples $(P<0.05)$ and by the Mann-Whitney test for non-normal distributions. Pearson $\chi^{2}$ analysis was applied for class variables. By means of the Pearson correlation coefficient, the associations between autoantibody titres and continuous variables in the total group were quantified.
To adjust differences between cases and controls for possible confounders, multiple linear regression was used. Stratified analysis was performed to identify confounders or effect modifiers. Odds ratios were calculated to quantify the association between autoantibody titre and coronary stenosis, the patients were divided into tertiles based on autoantibody titres in the hospital or population control group. Multiple logistic regression adjusted the odds ratio for potential confounders.

\section{Results}

In Table 1 the baseline characteristics of the three study groups are presented. The population control group was slightly, though significantly, younger than the two hospital groups. No differences were seen for body mass index (BMI). The hospital control group had higher HDL (highdensity lipoprotein) and lower LDL and triglycerides than the cases. The population controls had lower total cholesterol, HDL, LDL and systolic and diastolic blood pressure than the cases. After adjustment for age and smoking habits, the significant difference in HDL disappeared.

Autoantibody titres between cases $(1.44 \pm 1.82$ $($ mean \pm S.D. $)$ ), hospital controls $(1.46 \pm 1.40)$ and population controls $(1.62 \pm 1.95)$ were not significantly different. Fig. 1 shows frequency histograms of the autoantibody titres of the three 


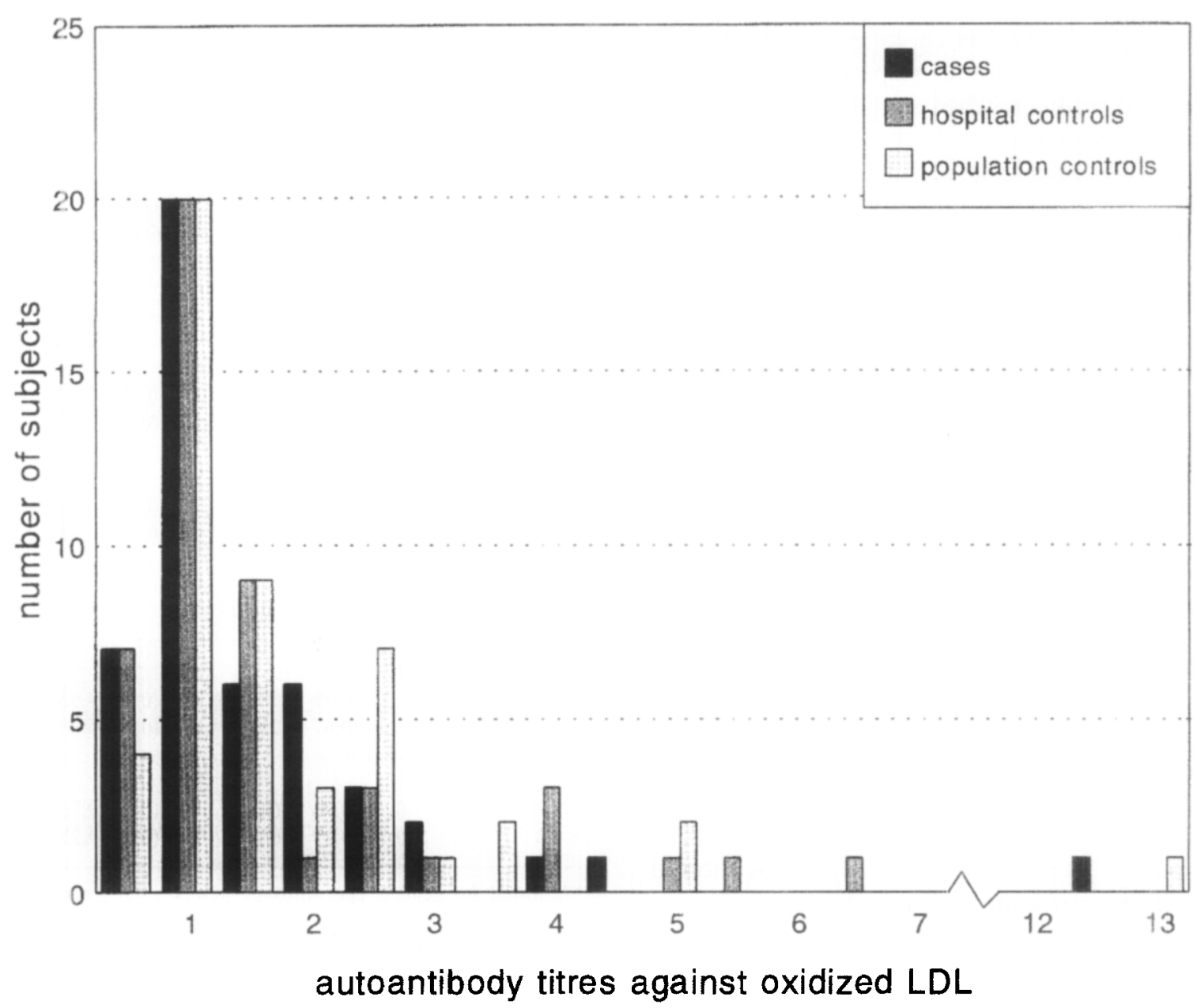

Fig. 1. Distribution of autoantibody levels against MDA-LDL among cases, hospital controls and population controls.

study groups. At the 1:8 and 1:32 dilutions, the autoantibody response to native LDL was measured. In 42 out of 143 persons, a response higher than 0.2 OD in both dilutions was found. These higher responses to native LDL were equally distributed over the three groups as determined with frequency calculations. Titres to native LDL (mean $( \pm$ S.D.)) were similar for the three groups. The OD assessed at dilution 1:8 were 0.34 $\pm 0.35,0.37 \pm 0.36$ and $0.32 \pm 0.35$ and at the $1: 32$ dilution $0.23 \pm 0.31,0.22 \pm 0.22$ and 0.21 \pm 0.20 for cases, hospital controls and population controls, respectively. None of the differences reached significancy.
Table 2 presents correlation coefficients for the total population between risk factors for CVD and autoantibody titres. Only BMI and HDL showed a significant relationship with autoantibodies. When LDL is being oxidized, a series of oxidative products of cholesterol are produced $[27,28]$. We, therefore, also assessed the relationship between cholesterol oxidation products (total oxysterols, $7 \alpha-\mathrm{OH}$ cholesterol (the main oxysterol, but also an important intermediate in the bile acid synthetic pathway) and total oxysterols without $7 \alpha-\mathrm{OH}$ cholesterol) and autoantibody titres in the case and the hospital control group. Correlations were $-0.05,-0.02$ and -0.07 for 
total oxysterols, $7 \alpha-\mathrm{OH}$ cholesterol and total minus $7 \alpha-\mathrm{OH}$ cholesterol, respectively. None of these correlations reached significance.

Odds ratios for the risk of CVD and autoantibody titre were calculated with logistic regression analyses for tertiles of autoantibody titre for cases and hospital controls and for cases and population controls. Results are shown in Table 3a. No significant associations were observed for autoantibody titres and CVD.

Additionally, we performed the analysis on data obtained by using the calculation method proposed by Salonen et al. [9], in which autoantibody titres are expressed as the ratio titre (binding to MDA-LDL divided by binding to native $\mathrm{LDL}$, both as OD). The mean ( \pm S.D.) ratio titres for cases, hospital controls and population controls were $4.54 \pm 2.96,4.26 \pm 2.72$ and $4.90 \pm 3.06$, respectively. Comparable to the above mentioned approach, no relevant differences among the groups were found.

When assessing the correlation coefficients between the ratio titre and risk factors for CVD, none of the variables age, number of cigarettes, BMI, systolic and diastolic blood pressure, total cholesterol, HDL, LDL and triglycerides showed a significant association (Table 2).

Odds ratios calculated for tertiles of the ratio titre in the control group are presented in Table $3 b$. No significant association was found between

Table 2

Correlations for all data between autoantibody titres and risk factors for CVD

\begin{tabular}{lcc}
\hline Total $(n=143)$ & Autoantibody titre & Ratio titre* \\
\hline Age & -0.01 & -0.14 \\
Number of & 0.06 & -0.08 \\
cigarettes/day & & \\
Body mass index & $0.20^{* *}$ & 0.09 \\
HDL & $-0.19^{* *}$ & -0.15 \\
Total cholesterol & -0.08 & -0.13 \\
Triglycerides & 0.03 & 0.02 \\
LDL & -0.03 & -0.10 \\
Systolic pressure & 0.05 & 0.04 \\
Diastolic pressure & 0.00 & 0.02 \\
\hline
\end{tabular}

*Autoantibody titres were calculated according to the method proposed by Salonen et al. [9].

${ }^{* *} P<0.05$
Table 3

Odds ratios and $95 \%$ confidence intervals (CI) for the risk of CVD in tertiles of auto antibody titres in the controlgroup, for case and hospital control groups and cases and population controls

\begin{tabular}{|c|c|c|}
\hline & Age-adjusted & $\begin{array}{l}\text { Multivariate } \\
\text { adjusted* }\end{array}$ \\
\hline \multicolumn{3}{|c|}{ (a) Autoantibody } \\
\hline \multicolumn{3}{|c|}{ titre } \\
\hline \multicolumn{3}{|c|}{ Cases hospital controls } \\
\hline$<0.76$ & 1.0 & 1.0 \\
\hline $0.76-1.17$ & $0.76(0.27-2.14)$ & $0.63(0.21-1.93)$ \\
\hline$>1.17$ & $1.09(0.40-2.95)$ & $0.77(0.26-2.27)$ \\
\hline \multicolumn{3}{|c|}{ Cases/population controls } \\
\hline$<0.75$ & 1.0 & 1.0 \\
\hline $0.75-1.42$ & $1.09(0.39-3.07)$ & $1.32(0.45-3.89)$ \\
\hline$>1.42$ & $0.90(0.32-2.56)$ & $1.08(0.36-3.25)$ \\
\hline \multicolumn{3}{|c|}{ (b) Ratio titre ${ }^{* * *}$} \\
\hline \multicolumn{3}{|c|}{ Cases/hospital controls } \\
\hline$<2.2$ & 1.0 & 1.0 \\
\hline $2.2-4.9$ & $2.22(0.75-6.58)$ & $1.51(0.46-4.95)$ \\
\hline$>4.9$ & $2.04(0.67-6.21)$ & $1.60(0.49-5.23)$ \\
\hline \multicolumn{3}{|c|}{ Cases/population controls } \\
\hline$<3.0$ & 1.0 & 1.0 \\
\hline $3.0-5.9$ & $0.98(0.36-2.68)$ & $0.93(0.32-2.76)$ \\
\hline$>5.9$ & $0.71(0.25-2.06)$ & $0.74(0.25-2.22)$ \\
\hline
\end{tabular}

*Adjusted for gender, age, smoking habits, HDL, body mass index.

${ }^{* *}$ Autoantibody titres were calculated according to the method proposed by Salonen et al. [9].

cases and hospital controls and between cases and population controls. Adjustment for gender, age, smoking habits, HDL and BMI had no impact on the results.

\section{Discussion}

In this study, no association between coronary heart disease and autoantibody titres was found.

It is unlikely that the absence of differences in autoantibody titres is due to flaws in the study design. Blood samples were stored at $-80^{\circ} \mathrm{C}$ or $-20^{\circ} \mathrm{C}$ degrees. There is no reason to assume that differences in storage temperature have affected the association, as autoantibody titres in 
plasma at the different storage temperatures were within the same range. Storage time for the three groups was comparable.

As it is conceivable that dietary or life-style changes may affect LDL oxidation in vivo [29-32] and thus may alter autoantibody production, the cases and hospital controls were examined within 2 months after the angiography. Thus, dietary and life-style changes as a response to the cardiology report are restricted.

The two hospital groups were slightly older than the population group (mean age of 54 and 50 for hospital and population groups, respectively). This could have introduced bias, but no association between autoantibody titres and age was found. Further, the result could have been biased by smoking habits, since there were more smokers in the population control group. Smoking might be related to oxidative stress [33-36] and thus could increase oxidation of LDL. Yet, no difference in autoantibody titres between smokers and non-smokers was found and calculation of corre'Ttions between autoantibody titres and number of cigarettes smoked did not produce a relevant association. In addition, in a previous report we did not observe an effect of smoking on susceptibility of LDL to oxidation [36].

We compared the autoantibody titres of the cases to both a hospital and a population control group. An objective discrimination between cases and hospital controls is possible based on the angiographical data, implying as a control group a group with documented minor stenosis. However, in the control group, 64\% were scored as having no stenosis, $23 \%$ had less than $10 \%$ stenosis in the 3 vessels and the mean percentage stenosis over the 3 vessels did not exceed $30 \%$. The population control group was a selection of healthy men and women without self-reported history of CVD. However, we cannot rule out the possibility of people with unknown, clinically non-manifested CVD entering the control group.

In this study, we defined autoantibody titres in two different ways: one related to a reference line constructed from the response to a reference plasma and the other being the ratio between the response to MDA-LDL and that to native LDL. The advantage of the first method is the use of several dilutions. The autoantibody titres presented are generally the mean of the autoantibody titres obtained at four dilutions. We believe to have thus reduced the approximation error. When plotting the OD against the concentration, individual curves do not parallel each other. As pointed out by Virella et al. [19], we therefore should not use these autoantibody titres as an absolute measure, but rather as an indicator of autoantibody concentrations. The second method for expressing autoantibody titres was calculated at the $1: 8$ and 1:32 dilutions. Both methods were significantly correlated $(r=0.34, P<0.001)$. As both ways of expressing the data generate the same result, it is justified to conclude that there is no reason to assume that our result can be ascribed to our definition of autoantibody titres.

The results of our study are consistent with reports from several groups, in which no difference in levels of antibodies were found [6,17-19], but are inconsistent with others $[7,9,10,12-14]$. In most studies, elevated levels of autoantibodies against epitopes of oxidized LDL are reported both in subjects with coronary heart disease and in healthy controls. Findings of Maggi et al. [10], Salonen et al. [9], Puurunen et al. [13], as well as the results of Virella et al. [18] who described higher (though not significantly higher) autoantibody titres in hyperlipidaemic persons and in subjects with minor atherosclerosis in comparison to persons with known CVD, support the idea that antibodies are not an indicator of the severity of atherosclerosis, i.e. the extent of thickening of the vessel wall, but can be used as an indicator for an active atherogenic process. In our study, no data on the change in extent of stenosis in recent years were available. We, therefore, can not exclude the possibility that subjects were in a stable state of atherogenesis. This may provide an explanation for the lack of difference in our study. Another explanation for not finding a relation with the extent of CVD is pointed out by Virella et al. [19] who suggest that different persons may have different populations of antibodies with a different affinity to antigens.

We conclude that this study does not support an association between autoantibody titres to oxidized LDL and thickening of the vessel wall. We 
suggest that clinical studies focus on assessment of the relationship between autoantibody levels and development of new lesions, e.g. by measurement of intima-media thickening by ultrasound.

\section{Acknowledgements}

This work was supported by a grant from the Netherlands Heart Foundation (grant 90.309).

\section{References}

[1] Steinberg D, Parthasarathy S, Carew TE, Khoo JC, Witztum JL. Beyond cholesterol: Modifications of low density lipoprotein that increase its atherogenicity. $\mathrm{N}$ Engl J Med 1989;320:915.

[2] Steinbrecher UP, Zhang $H$, Lougheed M. Role of oxidatively modified LDL in atherosclerosis. Free Rad Biol Med 1990;9:155.

[3] Witztum JL, Steinberg D. Role of oxidized low density lipoprotein in atherogenesis. J Clin Invest 1991;88:1785.

[4] Esterbauer H, Gebicki J, Puhl H, Jürgens G. The role of lipid peroxidation and antioxidants in oxidative modification of LDL. Free Rad Biol Med 1992;13:341.

[5] Palinski W, Ylä-Herttuala S, Rosenfeld ME, Butler SW, Socher SA, Parthasarathy S, Curtiss LK, Witztum JL. Antisera and monoclonal antibodies specific for epitopes generated during oxidative modification of low density lipoprotein. Arteriosclerosis 1990;10:325.

[6] Palinski W, Rosenfeld ME, Ylä-Herttuala S, Gurtner GC, Socher SS, Butler SW, Parthasarathy S, Carew TE, Steinberg D, Witztum JL. Low density lipoprotein undergoes oxidative modification in vivo. Proc Natl Acad Sci 1989;86:1372.

[7] Parums DV, Brown DL, Mitchinson MJ. Serum antibodies to oxidized low density lipoprotein and ceroid in chronic periaortitis. Arch Pathol Lab Med 1990;114:383.

[8] Orekhov AN, Tertov VV, Kabakov AE, Adamova IY, Pokrovsky SN, Smirnov VN. Autoantibodies against modified low density lipoprotein. Arterioscl Thromb 1991;11:316.

[9] Salonen JT, Ylä-Herttuala S, Yamamoto R, Butler S, Korpela H, Salonen R, Nyyssönen K, Palinski W, Witztum JL. Autoantibody against oxidised LDL and progression of carotid atherosclerosis. Lancet 1992;339;883.

[10] Maggi E, Finardi G, Poli M, Bollati P, Filipponi M, Stefano PL, Paolini G, Grossi A, Clot P, Albano E, Bellomo G. Specificity of autoantibodies against oxidized LDL as an additional marker for atherosclerotic risk. Coronary Artery Disease 1993;4:1119.

[11] Craig WY, Poulin SE, Nelson CP, Ritchie RF. Elisa of IgG antibody to oxidized Low Density Lipoprotein: effects of blocking buffer and method of data expression. Clin Chem 1994;40:882.

[12] Maggi E, Chiesa R, Melissano G, Castellano R, Astore D, Grossi A, Finardi G, Bellomo G. LDL oxidation in patients with severe carotid atherosclerosis. Arterioscl Thromb 1994;14:1892.

[13] Puurunen M, Mänttäri $M$, Manninen V, Tenkanen L, Alfthan G, Ehnholm C, Vaarala O, Aho K, Palosuo T. Antibody against oxidized low-density lipoprotein predicting myocardial infarction. Arch Intern Med 1994;154:2605.

[14] Maggi E, Marchesi F, Ravetta V, Martignoni A, Finardi G, Bellomo G. Presence of autoantibodies against oxidatively modified low-density lipoprotein in essential hypertension: A biochemical signature of an enhanced in vivo low-density lipoprotein oxidation. J Hypert 1995;13:129.

[15] Ylä-Herttuala S, Palinski W, Butler SW, Picard S, Steinberg D, Witztum JL. Rabbit and human atherosclerotic lesions contain IgG that recognizes epitopes of oxidized LDL. Arterioscler Thromb 1994;14:32.

[16] Rosenfeld ME, Palinski W, Ylä-Herttuala S, Butler S, Witztum JL. Distribution of oxidation specific lipidprotein adducts and apolipoprotein $B$ in atherosclerotic lesions of varying severity from WHHL rabbits. Arteriosclerosis 1990;10:336.

[17] Tatzber F, Rabl H, Koriska K, Erhart U, Puh1 H, Waeg G, Krebs A, Esterbauer $H$. Elevated serum neopterin levels in atherosclerosis. Atherosclerosis 1991;89:203.

[18] Schumacher M, Eber B, Tatzber F, Kaufman P, Esterbauer $\mathrm{H}$, Klein $\mathrm{W}$. LDL oxidation and coronary atherosclerosis (letter). Lancet 1992;340:123.

[19] Virella G, Virella I, Leman RB, Pryor MB, Lopes-Virella MF. Anti-oxidized low density lipoprotein antibodies in patients with coronary heart disease and normal healthy volunteers. Int J Clin Lab Res 1993;23:95.

[20] Verschuren WMM, Van Leer EM, Blokstra A, Seidell JC, Smit HA, Bueno de Mesquita HB, Oberman-de Boer GL, Kromhout D. Cardiovascular disease risk factors in the Netherlands. Neth J Cardiol 1993;4:205.

[21] Bos ES, Van der Doelen AA, Van Rooy N, Schuurs AHWM. 3,3 $3,5,5^{1}$ Tetra-methylbenzidine as an ames test negative chromogen for horse radish peroxidase in enzyme immunoassay. J Immunoassay 1981;2:187.

[22] Sullivan DR, Kruijswijk Z, West CE, Kohlmeier M, Katan MB. Determination of serum triglycerides by an accurate enzymatic method not affected by free Glycerol. Clin Chem 1985;31:1227.

[23] Warnick GR, Benderson J, Albers JJ. Dextran Sulfate$\mathrm{Mg} 2+$ precipitation procedure for quantitation of high density lipoprotein cholesterol. Clin Chem 1982;28:1379.

[24] Friedewald WT, Levy R, Fredrickson DS. Estimation of the concentration of LDL-cholesterol in plasma without the use of the preparative ultracentrifuge. Clin Chem 1972;18:499.

[25] Rifai N, Warnick GR, McNamara JR, Belcher JD, Grinstead GF, Frantz ID. Measurement of low density lipoprotein cholesterol in serum: a status report. Clin Chem 1992;38:150. 
[26] Dixon WJ, (ed). BMDP Statistical software manual version 7.0, California, 1992.

[27] Jialal I, Freeman DA, Grundy S. Varying susceptibility of different low density lipoproteins to oxidative modification. Arterioscl Thromb 1991;11:482.

[28] Liu K, Cuddy E, Pierce GN. Oxidative status of lipoproteins in coronary disease patients. Am Heart J 1992;123:285.

[29] Niki E. Antioxidants in relation to lipid peroxidation. Chem Phys Lipids 1987;44:227.

[30] Packer L. Protective role of vitamin E in biological systems. Am J Clin Nutr 1991;53:S1050.

[31] Princen HMG, Van Duyvenvoorde W, Buytenhek R, Van der Laarse A, Van Poppel G, Gevers Leuven JA, Van Hinsbergh VWM. Supplementation with low doses of vitamin $\mathrm{E}$ protects $\mathrm{LDL}$ from lipid peroxidation in men and women. Arterioscler Thromb Vasc Biol 1995;15:325.

[32] Reaven PD, Parthasaraty S, Grasse BJ, Miller E, Almazan F, Mattson FH, Khoo JC, Steinberg D, Witztum J. Feasibility of using an oleate-rich diet to reduce the susceptibility of low density lipoprotein to oxidative modification in humans. Am J Clin Nutr 1991;54:701.

[33] Pryor WA, Hales BJ, Premovic PJ, Church DF. The radicals in cigarette tar: their nature and suggested physiological implications. Science 1983;220:425.

[34] Stryker WS, Kaplan LA, Stein EA, Stampfer MJ, Sober A, Willett WC. The relation of diet, cigarette smoking, and alcohol consumption to plasma $\beta$-carotene and $\alpha$-tocopherol levels. Am J Epidemiol 1988;127:283.

[35] Harats D, Ben-Naim M, Dabach Y, Hollander G, Havivi E, Stein O, Stein Y. Effect of vitamin C and E supplementation on susceptibility of plasma lipoproteins to peroxidation induced by acute smoking. Atherosclerosis 1990;85:47.

[36] Princen HMG, Van Poppel G, Vogelezang C, Buytenhek R, Kok FJ. Supplementation with vitamin $E$ but not $\beta$-carotene in vivo protects low density lipoprotein from lipid peroxidation in vitro. Effect of cigarette smoking. Arterioscler Thromb 1992;12:554. 